The final place of labetalol for hypertension must await the results of forthcoming comparative studies. Our data indicate that it is well suited for treating mild and moderate hypertension, in which we restored the blood pressure to normal in $75 \%$ of patients with a dose of $200 \mathrm{mg}$ thrice daily. Evident advantages over pure beta-blocking substances include safer use in patients with initial bradycardia; in patients with atrioventricular conduction disturbances; and in asthmatics, who do not exhibit bronchoconstriction when on labetalol. ${ }^{16}$

\section{References}

1 Prichard, B N C, and Gillam, P M S, British Medical fournal, 1964, 2, 725 2 Prichard, B N C, and Gillam, P M S, British Medical fournal, 1969, 1, 7.
3 Frohlich, E D, et al, Circulation, 1968, 37, 417.

Hansson, L, et al, Klinische Wochenschrift, 1972, 50, 364.

${ }^{5}$ Somer, T, Luomanmäki, K, and Frick, M H, Acta Medica Scandinavica, 1974, suppl No 554, p 33.

6 Furberg, C, et al, Acta Medica Scandinavica, 1969, 186, 447.

' Lydtin, H, et al, American Heart fournal, 1972, 83, 589.

${ }^{8}$ Prichard, B N C, et al, British Heart fournal, 1970, 32, 236.

9 Hansson, L, et al, Acta Medica Scandinavica, 1974, 196, 27.

10 Tarazi, R C, and Dustan, H P, American fournal of Cardiology, 1972, 29, 633.

${ }^{11}$ Farmer, J B, et al, British fournal of Pharmacology, 1972, 45, 660.

12 Kennedy, I, and Levy, G P, British fournal of Pharmacology, 1975, 53, 585.

13 Richards, D A, et al, British fournal of Clinical Pharmacology, 1974, 1, 505.

14 Collier, J G, et al, British fournal of Pharmacology, 1972, 44, 286.

15 Katila, M, and Frick, M H, International fournal of Clinical Pharmacology, Therapy and Toxicology, 1970, 4, 111.

16 Skinner, C, Gaddie, J, and Palmer, K N V, British Medical fournal, 1975, $1,59$.

\title{
Four new anti-inflammatory drugs: responses and variations
}

\author{
E C HUSKISSON, D L WOOLF, H W BALME, JANE SCOTT, SUE FRANKLYN
}

British Medical fournal, 1976, 1, 1048-1049

\section{Summary}

Ninety patients with rheumatoid arthritis completed a double-blind crossover trial comparing fenoprofen, ibuprofen, ketoprofen, and naproxen. Fenoprofen and naproxen were slightly more effective than the other two drugs but there were striking individual variations in response. Groups of patients could be identified who preferred each of the four drugs. The commonest side effects were those related to the upper gastrointestinal tract; these showed individual variation and seldom occurred with more than one or two of the drugs. Side effects were least common with ibuprofen and naproxen. Since naproxen combined greater effectiveness with a lower incidence of side effects it must be regarded as the first choice among these drugs. It may be necessary to try several drugs before finding the right one for a particular patient.

\section{Introduction}

If aspirin is no longer the first line of treatment of rheumatoid arthritis $^{1-3}$ its place must surely have been taken by one of the propionic acid derivatives. But which one ? The four currently available compounds are claimed to have analgesic potency comparable to that of aspirin but with a much lower incidence of side effects. We have compared their effectiveness and tolerability.

\footnotetext{
Department of Rheumatology, St Bartholomew's Hospital, London EC1A 7BE

E C HUSKISSON, MD, MRCP, senior lecturer

H W BALME, MD, FRCP, consultant physician

JANE SCOTT, SRN, SCM, measurement technician

SUE FRANKLYN, MCSP, measurement technician

Wanstead Hospital, London E11

D L WOOLF, MRCS, LRCP, DPHYSMED, consultant rheumatologist
}

\section{Methods}

A total of 105 outpatients with definite or classic rheumatoid arthritis as defined by the ARA criteria were admitted to the study. They were treated for two weeks with each of four drugs-fenoprofen $2.4 \mathrm{~g}$ daily, ibuprofen $1.2 \mathrm{~g}$ daily, ketoprofen $150 \mathrm{mg}$ daily, and naproxen $500 \mathrm{mg}$ daily. The order of treatment was randomised and balanced in a latin-square design. Patients who withdrew from the study for reasons unrelated to treatment were replaced to ensure that at least three complete balanced blocks of 24 patients were included. The doses used were recommended by the manufacturers at the time of the study. To avoid patients recognising tablets that they might already have received each drug was supplied in a formulation different from the marketed form; fenoprofen was supplied in $300 \mathrm{mg}$ white capsules, ibuprofen in $200 \mathrm{mg}$ white tablets, ketoprofen in $25 \mathrm{mg}$ white capsules, and naproxen in $125 \mathrm{mg}$ yellow capsules. The bioavailability of the preparations was confirmed. Simple analgesics were allowed during the study, and 16 patients taking small doses of corticosteroids continued with these. No other antirheumatic treatment was allowed.

At the end of each fortnight measurements were made of pain using a visual analogue scale, the duration of morning stiffness, and proximal interphalangeal joint circumference. A preference was sought for each pair of treatments, and after the third and fourth treatment periods a rank order of preference was noted. The patient were asked at the end of each treatment period: "Has the treatment upset you in any way ?" Any side effects elicited were recorded as slight, moderate, or severe. Returned tablets were counted. Measurements in a particular patient were carried out by the same observer at the same time of day. The observers were not aware of which treatment a patient was receiving.

Non-parametric statistical tests were applied to all measurements except joint size because the distribution of results was not normal. Friedman's two-way analysis of variance by ranks was used for measurements of pain, duration of morning stiffness, and preference. Wilcoxon's test was used for side-effect scores. Analysis of variance was applied to measurements of joint size.

\section{Results}

Ninety patients completed the trial. The mean pain scores (table I) were significantly lower in patients receiving fenoprofen and naproxen than in those receiving ibuprofen and ketoprofen $\left(\chi^{2}=\right.$ $12.04 ; \mathrm{P}<0.01)$. Fenoprofen and naproxen were also significantly more effective in terms of both the duration of morning stiffness $\left(\chi^{2}=17.7 ; P<0.001\right)$ and preference $\left(\chi^{2}=10.54 ; P<0.02\right)$. There was no significant difference between the effects of the four drugs on 
TABLE I-Mean pain scores, duration of morning stiffness, and joint size after two weeks' treatment with each drug and analysis of preference

\begin{tabular}{|c|c|c|c|c|c|}
\hline & Pain & $\begin{array}{l}\text { Duration of } \\
\text { morning } \\
\text { stiffness } \\
\text { (min) }\end{array}$ & $\begin{array}{l}\text { Joint } \\
\text { size } \\
(\mathrm{mm})\end{array}$ & $\begin{array}{l}\text { No of patients } \\
\text { selecting } \\
\text { drug of } \\
\text { first choice* }\end{array}$ & $\begin{array}{l}\text { Preference } \\
\text { (sum of } \\
\text { ranks) }\end{array}$ \\
\hline $\begin{array}{l}\text { Fenoprofen } \\
\text { Ibuprofen } \\
\text { Ketoprofen } \\
\text { Naproxen }\end{array}$ & $\begin{array}{l}10 \cdot 6 \\
11 \cdot 6 \\
11 \cdot 4 \\
10 \cdot 3\end{array}$ & $\begin{array}{l}63 \cdot 0 \\
98 \cdot 2 \\
89 \cdot 0 \\
70 \cdot 3\end{array}$ & $\begin{array}{l}568 \cdot 0 \\
568 \cdot 5 \\
569 \cdot 2 \\
568 \cdot 3\end{array}$ & $\begin{array}{l}29 \\
13 \\
12 \\
34\end{array}$ & $\begin{array}{l}210 \cdot 5 \\
245 \cdot 0 \\
241 \cdot 0 \\
203 \cdot 5\end{array}$ \\
\hline
\end{tabular}

*Two additional patients divided their first choice between two drugs.

joint size. Neither pain nor morning stiffness showed any tendency to change with time, and about the same number of patients preferred the first, second, third, and fourth treatment periods. Joint size, however, diminished progressively and significantly during the study $(\mathrm{F}=5.6 ; \mathrm{P}<0.001)$.

The most common side effects were those related to the upper gastrointestinal tract. In decreasing order of frequency they were indigestion, heartburn, nausea, abdominal pain, flatulence, vomiting, and anorexia. Side-effect scores, as shown in table II, represent the total for all patients, severe side effects scoring 3, moderate 2 , and mild 1. Gastric side effects were significantly more common on fenoprofen and ketoprofen than on ibuprofen and naproxen $(P<0.01)$

TABLE II-Side-effect scores two weeks after treatment with each drug and mean number of days' supply of tablets returned

\begin{tabular}{l|c|c|c}
\hline & $\begin{array}{c}\text { Total } \\
\text { side-effect score }\end{array}$ & $\begin{array}{c}\text { Gastric } \\
\text { side-effect score }\end{array}$ & $\begin{array}{c}\text { Returned tablets } \\
\text { (No of days' supply) }\end{array}$ \\
\cline { 2 - 3 } Fenoprofen & 171 & 119 & $1 \cdot 6$ \\
Ibuprofen & 67 & 36 & $1 \cdot 1$ \\
Ketoprofen & 114 & 87 & $1 \cdot 8$ \\
Naproxen & 62 & 43 & 0.4
\end{tabular}

The differences between fenoprofen and ketoprofen and between ibuprofen and naproxen were not significant $(P>0 \cdot 1)$. The same pattern of incidence was seen with all the gastric side effects except flatulence, which was commonest in patients receiving ketoprofen.

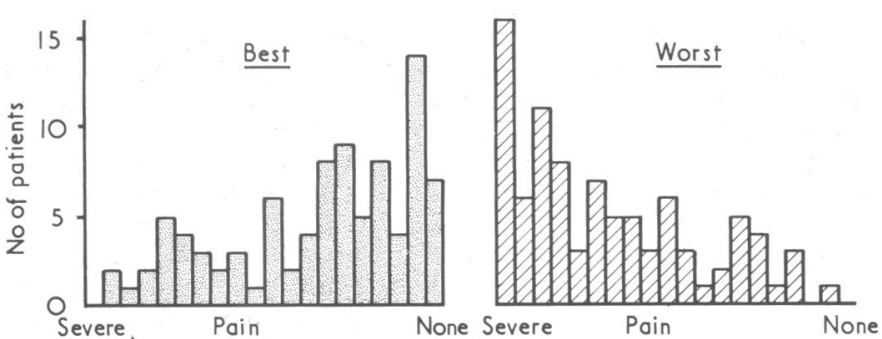

FIG 1-Pain scores of 90 patients each receiving two weeks' treatment with all four anti-inflammatory drugs. Upper distribution is made up of lowest pain scores for each patient and lower distribution of highest pain scores.

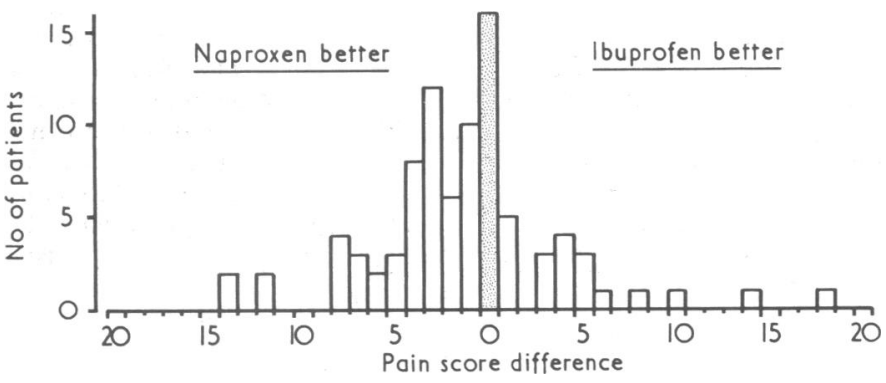

FIG 2-Distribution of differences in pain scores measured after two weeks' treatment with naproxen and those measured after treatment with ibuprofen. Shaded area represents number of patients in whom there was no difference. Those on left represent differences in favour of naproxen and those on right those in favour of ibuprofen.
Various other side effects occurred more commonly with fenoprofen than with the other drugs, though no particular complaints could be identified as the cause of this difference. Fewer daily doses of naproxen than of the other three drugs were returned at the end of the study (table II).

During the study it became clear that many patients were strikingly improved by one or other of the drugs, and these large differences were not reflected in the mean pain scores. The difference between the best and worst drugs for a particular patient was often large (fig 1). The differences in pain scores between one of the more effective drugs, naproxen, and one of the less effective, ibuprofen, are shown in fig 2. Clearly though the overall distribution favoured naproxen, there were many patients in the tail of the distribution for whom ibuprofen was much more effective than naproxen. The same individua variation was apparent with the side effects. Out of 66 patients with upper gastrointestinal effects only two had these side effects with all four drugs, and only seven had them with three of the four drugs.

Fifteen patients were withdrawn from the study before completing all four treatment periods. Neither measurements of effectiveness nor side effects reported by these patients were included in the analysis. One patient was withdrawn while receiving naproxen because of haematemesis and melaena. Two patients had various side effects during the first treatment period and preferred to return to their previous treatment. Three patients were withdrawn because of unrelated illnesses, and three because of admission to hospital. Four patients failed to attend for assessment, one never got around to taking the tablets, and one had side effects that prevented her from taking more than a few tablets in each treatment period.

\section{Discussion}

The first choice among these propionic acid derivatives must be naproxen, which combined the greatest effectiveness with the lowest incidence of side effects. Fenoprofen was as effective but caused many more side effects. Ibuprofen was as well tolerated as naproxen but less effective. Against naproxen must be set the occasional occurrence of gastrointestinal haemorrhage. ${ }^{45}$ The relative frequency of this is difficult to ascertain, especially since there are considerable differences in the usage of the four drugs. Clearly, however, second, third, and even fourth choices are useful with this group of drugs because of the wide variation in individual responses in terms of both effectiveness and the incidence of side effects. Since we cannot yet predict which patients will respond to a particular drug it may be necessary to try them all to find the best. Drugs of this type are thought to be fully effective within a week. ${ }^{2}$ Thus one week of treatment should be prescribed in the first instance and an alternative drug used if it is not effective within that time.

It has been suggested that gastric side effects are an inevitable accompaniment of anti-inflammatory activity, but our findings do not support this view-one of the more effective drugs was one of the less likely to upset the stomach.

Our results agree with those of Reynolds and Whorwell, who found fenoprofen and naproxen superior to ibuprofen in terms of pain and morning stiffness; with a much smaller sample their results could not be expected to achieve statistical significance.

We are indebted for help with this study to Mrs $\mathbf{R}$ Cromack, Miss $M$ Leighton, Miss $E$ Thornton, other members of the staff of the departments of rheumatology at Wanstead and St Bartholomew's Hospitals, and the pharmaceutical companies, who supplied the drugs.

\section{References}

${ }^{1}$ Huskisson, E C, Reports on Rheumatic Diseases, No 54. London, Arthritis and Rheumatism Council, 1974.

${ }^{2}$ Huskisson, E C, et al, British Medical fournal, 1974, 1, 176.

${ }^{3}$ Lee, P, et al, British Medical fournal, 1974, 1, 424.

4 Beck, E R, and Hayes-Allen, M C, British Medical fournal, 1974, 1, 572.

5 Hart, F D, and Matts, S G F, British Medical fournal, 1974, 2, 51 .

${ }^{6}$ Reynolds, P M G, and Whorwell, P J, Current Medical Research and Opinion, 1974, 2, 461 . 